\title{
1 Limited genetic variation for male mating success reveals low 2 evolutionary potential for thermal plasticity in Drosophila \\ 3 melanogaster
}

4

5 John T. Waller ${ }^{\dagger}$ (corresponding author) john.waller@biol.lu.se +46070 4887577

$6 \quad$ Anna Kell ${ }^{\dagger}$

$7 \quad$ Mireia Ballesta ${ }^{\dagger}$

$8 \quad$ Aude Giraud ${ }^{\dagger}$

9 Jessica K. Abbott ${ }^{\dagger}$

10 Erik I. Svensson ${ }^{\dagger}$

$11{ }^{\dagger}$ Evolutionary Ecology Unit, Department of Biology, Lund University, SE-223 62 Lund,

12 Sweden

13 Short Title: Limited genetic variation in thermal plasticity

14 Acknowledgements: We are grateful to anonymous referees for constructive criticisms earlier

15 drafts of this manuscript. Funding for this study has been provided by the Swedish Research

16 Council (VR; grant no. 621-2012-3768) and Gyllenstiernska Krapperupstiftelsen (grant no.

17 2014-0032) to E.I. S.

Data is archived on https://datadryad.org/ 
28

\section{Abstract}

Populations respond to novel environmental challenges either through genetic changes, through adaptive phenotypic plasticity for the traits in question, or by a combination of these factors. Here, we investigated the evolutionary potential of phenotypic plasticity for male mating success, locomotory ability, and heating rate (a physiological performance trait) in the fruitfly Drosophila melanogaster, using isogenic male lines from the Drosophila Reference Genome Panel (DGRP) and hemi-clonal males. We quantified thermal reaction norms of how male mating success changed in relation to a temperate gradient, ranging from cold $\left(18{ }^{\circ} \mathrm{C}\right)$ via optimal $\left(24{ }^{\circ} \mathrm{C}\right)$ to hot and stressful environments (either $30^{\circ} \mathrm{C}$ or $\left.36^{\circ} \mathrm{C}\right)$. We found significant differences in male mating success and locomotory performance between different lines, as well as significant main effects of temperature, but no significant genotype-byenvironment interactions (GEI:s). A statistical power analysis revealed that the variance explained by GEI:s for thermal plasticity using this sample size is likely to be modest or very small, and represent only $4 \%$ of the total variation in male mating success. The lack of strong GEI:s for these two behavioral traits contrast with the presence of significant GEI:s for male heating rate, as measured by thermal imaging (infrared camera technology). These results suggest that sexual selection through male mating success is not likely to be efficient in mediating evolutionary rescue through changed plasticity in response to changing temperatures.

\section{Keywords:}

additive genetic variation, fruit fly, infrared camera, sexual selection, insects, thermal imaging, thermal performance, thermal plasticity 


\section{Introduction}

55 Populations can respond to environmental challenges either evolutionarily through changes in

56 allele frequencies or through adjustments in phenotypic plasticity (Schlichting and Pigliccui

57 1998). Phenotypic plasticity is the capacity of a single genotype to change its phenotype under

58 different environmental conditions (Bradshaw 1965; Roff 1997; Pigliucci 2001). Phenotypic plasticity can increase a population's mean fitness across several environments, and plasticity might increase niche space and geographical range (Ayrinhac et al. 2004; Manenti et al. 2015; Mather and Schmidt 2017). Responding plastically to changing environmental conditions is, however, a short-term survival strategy for a population, as there are costs and limits to plasticity (Lande 2014; Murren et al. 2015; Sgro et al. 2016), which can limit the potential to respond to sustained environmental change (Gonzalez et al. 2013). Adaptive evolution of phenotypic plasticity requires not only that a population responds to changing environmental conditions, but the different genotypes must also differ in how they respond to these changing environmental conditions (Lande 2009; 2014; Chevin et al. 2010). A population must thus harbor enough standing genetic variation in environmental reaction norms to respond to sustained selection pressures driven by environmental change and thereby evolve adaptive phenotypic plasticity (Schlichting and Pigliucci 1998; Gonzalez et al. 2013). The presence of genetic variation in phenotypic plasticity is recorded by the presence of significant genotype-by-environment interactions (GEI:s)(Schlichting and Pigliucci 1998; Lande 2009). If a population lacks such genetic variation in reaction norm slopes, microevolutionary changes in plasticity will be prevented (Sisodia \& Singh 2010; Husby et al. 2010). 
78 Hansen and Houle (2004) argued that the vast majority phenotypic traits have large amounts

79 additive genetic variation, even when such traits show evidence of long term stasis in the

fossil record or in extant populations. However, and in contrast to this view, there are some

documented empirical examples where genetic variation for physiological traits has been

demonstrated to be low enough to act as an evolutionary limit (Blows \& Hoffmann 2005). If a

population is invariant in its evolutionary response to sustained environmental change, any

change outside of a critical range should rapidly lead to population decline and ultimately

extinction (Charmantier et al. 2008; Visser 2008; Chevin et al. 2010).

Thermal plasticity is a form of phenotypic plasticity that is particularly important for changes (Angilletta et al. 2002; Angiletta 2009). Many ectotherm species might already be close to their upper physiological thermal limits (Addo-Bediako et al. 2000; Deutsch et al. 2008; Kellermann et al. 2012). In particular, small insects and other ectotherms may lack the ability to buffer themselves against external temperatures altogether (Stevenson 1985). This might be reflected as canalization (i.e. low genetic variance in thermal reaction norms) resulting in low thermal plasticity (Angilletta et al. 2002; Charmantier et al. 2008). In general, we know relatively little about the amount of genetic variation in thermal plasticity in natural populations. Moreover, most previous studies on thermal adaptation and thermal plasticity in insects and other ectotherms focus on how temperature affects survival and hence the implications for natural selection. In contrast, the consequences of temperature challenges for sexual selection (e.g. how mating rates and mating success is affected by temperature and thermal plasticity) has seldom been a focus for empirical investigations (see Olsson et al. 
studies exploring the link between thermal adaptation and sexual selection include how melanin-based dark colouration affects body temperatures within local populations and across latitudinal clines (Punzalan et al. 2008; Svensson and Waller 2013), how different microclimatic environments reduces immigrant male viability (Gosden et al. 2015), how mating rates might be temperature-dependent (Olsson et al. 2011; Taylor et al. 2015) and a recent finding that postzygotic isolation evolves more rapidly between various species of Drosophila in hot tropical areas, compared to cooler temperate areas (Yukilevich 2013).

Isogenic Drosophila melanogaster lines offer an excellent opportunity to investigate genetic variation in thermal reaction norms. The Drosophila Genetic Reference Panel (DGRP) is a public resource consisting of more than 200 inbred lines derived from a population in Raleigh, North Carolina (Mackay et al. 2012). Since the lines are isogenic, any phenotypic differences between these lines can be attributed to genetic effects, provided that they are raised and kept under identical conditions. Here we investigate and quantify the amount of genetic variation in thermal reaction norms of 30 DGRP lines, using a hemiclonal experimental approach (Abbott \& Morrow 2011), and also by comparing these different DGRP-lines directly with each other. These DGRP lines should be representative sample and a snapshot of naturally segregating genetic variation in the local populations from which they were derived (Mackay et al. 2012) and have also been previously used them in a study on sexual selection on wing interference patterns (WIPs)(Katayama et al. 2014).

A necessary condition for the evolution of adaptive phenotypic plasticity in a novel thermal environment is that the population harbors enough standing genetic variation in the trait of interest (Chevin et al. 2010). A relatively low amount of genetic variation would indicate that 
127 the population is unlikely to respond evolutionarily to these novel thermal conditions. Here

128 we investigate how two behavioral traits important to male fitness - male locomotion and

129 mating success - are influenced by varying thermal conditions and whether these two fitness-

130 related traits show any evidence for genetic variation in plasticity. We used male locomotor

131 activity as a measure of performance as this trait is likely to be associated with fitness because

132 of its links with reproductive success, dispersal, predator avoidance, and foraging (Gilchrist,

133 1996; Roberts et al., 2003; Long \& Rice, 2007; Latimer et al. 2011). We complemented these

134 analyses of behavioral performance traits with an analysis of a physiological trait - heating

135 rate - using the technique of thermal imaging ("infrared camera") on a subset of these DGRP-

136 lines. Heating rate is also likely to covary with physiological performance and mating success,

137 especially in ectotherms. Thermal imaging is a technique by which body temperatures of both

138 endotherms and ectotherms can be quantified, under laboratory, semi-natural, and natural

139 field conditions (Tattersall et al 2009; Tattersall and Cadena 2010; Symonds and Tattersall

140 2010; Svensson and Waller 2013).

Methods

\section{Drosophila melanogaster sources}

Isogenic lines used in this experiment were obtained from the Drosophila melanogaster

Genetic Reference Panel (DGRP) of the Bloomington Stock Centre (Mackay et al. 2012), which were created after 20 generations of full sibling inbreeding of the stock inbred fly populations (Mackay et al. 2012). Wild type (LHm) flies were originally obtained from 
150 Harshman in central California in 1991 and they have been maintained since that time by L

151 Harshman (1991-1995), WR Rice (1995-2004) and EHM (2004-present) (Carter et al. 2009).

\section{Producing hemiclonal males from DGRP-lines}

154 A total of 16 male DGRP flies for each isogenic line were crossed with 16 wildtype virgin

155 LHm females (in a total of 992 vials). The outbred male offspring were then used for the

156 mating and locomotion assays. We refer to these outbred male flies as hemi-clones, following

157 previous terminology (Abbott and Morrow 2011). This outbreeding procedure was conducted

158 to reduce any inbreeding effects on mating behaviour that could potentially remain among the

159 DGRP-lines (Huang et al. 2012). Moreover, by comparing male mating success in the DGRP

160 background vs. mating success in a hemi-clonal background, we were also able to reduce the

161 effects of non-heritable genetic variation across the different genetic backgrounds. Additive

162 genetic variance in male mating success is expected to produce a significant correlation in

163 male mating success between the DGRP-lines and the corresponding male genotype in the

164 hemi-clonal background. Conversely, a weak correlation between male mating success in

165 these different genetic backgrounds would imply low additive genetic variance for this trait

166 and might also indicate a large non-additive effects, arising from e.g. epistatic genetic

167 variance (Meffert et al. 2002) or dominance variation (Merilä \& Sheldon 1999). All flies were

168 cultured in a $20 \mathrm{~mm}$ medium of cornmeal, yeast, and molasses and kept at $25^{\circ} \mathrm{C}$ in an

169 incubator, on a light-dark cycle of $12 \mathrm{hrs}: 12 \mathrm{hrs}$.

DGRP-lines and hemiclonal experiments

171 Two complementary groups of flies were used: 1) 32 pure isogenic DGRP lines, and 2) 30

172 hemi-clonal DGRP lines (Mackay et al. 2012). Throughout this paper, we refer to these

173 separate experimental fly categories as DGRP-lines and hemiclonal lines, respectively. For 
174 the 32 pure DGRP-lines, the mating assay was performed in three test temperatures: $18^{\circ} \mathrm{C}$

175 (cold), $24^{\circ} \mathrm{C}$ (optimal) and $30^{\circ} \mathrm{C}$ (hot). We performed three replicates for each line and

176 temperature treatments for these pure DGRP-lines for a total of 265 vials.

177 In a first pilot study using hemiclonal males, we selected 10 DGRP lines for outbreeding to

178 produce 10 groups of hemiclonal males. These 10 DGRP lines were specifically selected for

179 outbreeding because they showed variable patterns in their mating rates to different

180 temperatures in the initial mating assay with the 32 pure DGRP-lines. In general, however, the

181 individual patterns we observed in the pure DGRP lines were only weakly related to the

182 patterns in the outbred lines (Fig. 4) (Huang et al. 2012). Hemi-clones were produced by

183 mating 992 vials of 16 DGRP males with 16 virgin females from the outbred $\mathrm{LH}_{\mathrm{M}}$ population

184 (Chippindale et al. 2001). Male offspring from these crosses will therefore have one set of

185 DGRP autosomes and the $\mathrm{Y}$ in a random $\mathrm{LH}_{\mathrm{M}}$ background. For three test temperatures, $18^{\circ} \mathrm{C}$

186 (cold), $24^{\circ} \mathrm{C}$ (optimal) and $30^{\circ} \mathrm{C}$ (hot), we performed both mating and locomotion assays.

We followed up the first pilot hemiclonal study with a second study, where we used 30 isogenic lines (DGRP) to produce a new set of 30 hemiclonal groups of males. In this followup study, we performed mating and locomotion assays at $18^{\circ} \mathrm{C}$ (cold), $24^{\circ} \mathrm{C}$ (optimal), $30^{\circ} \mathrm{C}$ (hot) and we also added one additional temperature treatment at $36^{\circ} \mathrm{C}$ (extremely hot) (Trotta et al. 2006). This temperature range is similar to what has been used in other studies (Latimer et al. 2011). We performed six replicates for each line and temperature treatment in this assay, although the total number of replicates will be slightly greater for those lines in which the pilot study was also included. We pooled the results from first hemiclonal study with the second to increase statistical power, while accounting for the effect of experimental sessions as a block in our statistical analyses. 


\section{Mating assays}

199

200

201

202

203

204

205

206

207

208

209

210

211

212

Each line was anaesthetised with $\mathrm{CO}_{2}$ gas. Seven males per vial were collected and placed in separate 25 x 95 mm vials (with fly medium). Seven LHm virgin females were also collected per vial, and placed in separate vials. Vials of males and females were kept at $25^{\circ} \mathrm{C}$ overnight, to allow recovery from anaesthesia. For the experiment, vials containing hemiclonal males (one vial per line), and vials of LHm females were placed in an incubator at the test temperature and allowed to acclimatise for 30 minutes. After this time, the flies from one female vial were transferred without anaesthesia (“flipped”) into a male vial. Vials with males and females were shaken lightly to avoid early mating while the other vials were being combined. The vials, now with 14 flies in total, were placed back in the incubator at the test temperature for 1 hour as the mating assay was conducted. One vial for each of our clonal lines (hemi or pure) was placed in the incubator at a time. For each of the test temperatures, the number of copulating pairs was used a measure of male mating success. The number of mating males in each vial could thus vary from 0 to 7 , and it was recorded every 10 minutes (or 15 minutes for the pure lines) over a one hour period. Here, we are measuring a mating rate, which also captures any variation in the latency to mate. All observations were recorded each day between 9.00 and $17.00 \mathrm{hrs}$. We randomized the time of day for mating observations within each line.

\section{Locomotion assay}

After 30 minute period of incubation, and before the flies from the male and female vials were combined, the male vials were tapped to cause all the males to fall to the bottom of the food vial. We then recorded the time required for the fastest male fly to walk up the side of the vial from the bottom of the food to the top of the vial plug $(95 \mathrm{~mm})$. This was repeated three times for each line and we took the average value per vial (Gibert et al. 2001). 


\section{Heating rate assay}

223 Using a thermal imaging camera (NEC Avio Infrared Technologies H2640) and macro lens

224 (NEC Avio Infrared Technologies TH92-486), we recorded the heating rate of 10 DGRP lines

225 (see supplement for information about the specific DGRP lines used). Fly individuals from

226 each line were cooled in a climate chamber at $5^{\circ} \mathrm{C}$ for 3 minutes before being removed from

227 the chamber and allowed to heat up to room temperature (approximately $23^{\circ} \mathrm{C}$ ) in a petri dish.

228 Thermal images were taken every 5 seconds for around 30 seconds or when all the flies had

229 left the petri dish. Two experimental blocks of each line were performed. We recorded how

230 body temperature changed for each line over this time period by analyzing these thermal

231 images using the software provided by NEC Avio (see Svensson and Waller 2013 for more

232 methodological details).

\section{Statistical analyses}

234 All statistical analysis in this paper were conducted in R (R Development Core Team 2008).

235 R-code for all the analyses are uploaded to Dryad, and details are provided in the

236 Supplementary Material. To analyze the heating rates of 10 chosen DGRP lines, we

237 performed an analysis of variance with temperature at each time point as the dependent

238 variable. The following model was used: Temp $=$ Time + Line + Block + Time $*$ Line +

239 Time*Block + Temp*Line*Block.

241 For the hemi-clones, we performed a two-way analysis of variance (ANOVA) with the

242 number of matings at 10 minutes as the dependent variable, with line, temperature, and their

243 interactions as dependent factors. In this analysis, line and temperature were both treated as

244 categorical factors. In a follow-up analysis of these hemi-clonal males, we instead treated 
246 their two-way interactions with line (i.e. mating rate $=$ Temp + Line + Temp $*$ Line + Temp ${ }^{2}$

$247+$ Line $^{*} \mathrm{Temp}^{2}$ ). We chose to analyse temperature as both a continuous and categorical

248 variable because both analyses have useful interpretative value. In the analysis of the pure

249 DGRP-lines, we performed a similar two-way analysis of variance (ANOVA) with the

250 number of matings at 15 minutes as the dependent variable and line, temperature and their

251 interaction as independent dependent factors. In this analysis, line and temperature were also

252 both treated as categorical factors.

254 We additionally performed a repeated measures analysis on the hemiclonal lines using the Rpackage 'nlme' (Pinheiro et al. 2016). We used the number of matings as the dependent variable, and experimental temperature category $\left(18,24,30,36{ }^{\circ} \mathrm{C}\right.$ as different levels), line (the 30 hemi-clonal lines as different levels), and time (10, 20, 30, 40, 50, 60 minutes) were treated as fixed effects in this model. Vial and experimental block were treated as nested a random effects. This allowed us to control for the non-independence of the repeated mating counts over each vial.

The two-way interaction between line and temperature treatment in these tests, should reflect the magnitude and possible statistical significance of genotype-by-environment interaction with respect to thermal plasticity for male mating rate. Significant line-by-temperature interactions would thus indicate the presence of genetic variation in the thermal reaction norms of males belonging to different DGRP- and hemi-clones respond in terms of their mating success at different temperatures.

267 Finally, we performed a power analysis simulation to quantify the minimum amount of genetic variation in thermal reaction norms that we would be able to detect an effect in the 30 
on Dryad). To analysis variation in heating rate, we performed a two-way analysis of variance (ANOVA) with the average temperature at each time point as the dependent variable and line, time, and their interactions as dependent factors, while also controlling for a block effect. An analysis modelling mating rate as a proportion is presented in the Supplementary Material (Table S1).

\section{Results}

We found significant variation in mating rates and locomotory performance among lines, using both the hemi-clonal and the pure DGRP lines (Tables 1-4, S1, S2, S3; Fig. 1). As expected, all lines of both hemi-clonal and pure DGRP experimental categories responded plastically to the different temperature treatments (Fig. 2). Male mating rates and locomotory performance were significantly affected by temperature (Fig 2).

For all of our statistical analyses, and for neither the hemi-clonal nor the pure DGRP assays, we did not find any statistically significant interaction between line and temperature, that would be indicative of GEI:s (Fig. 1; Tables 1-3, S1, S2, S3). Moreover, we were not able to find any evidence for a statistically significant interaction between line and the squared temperature component (Table 3), i.e. neither the slopes nor the curvatures of the thermal response curves differed significantly between lines (Fig. 1).

Visual inspection of the thermal performance curves for male mating success in Fig. 1 revealed that 24 out of the 30 hemi-clonal lines peaked at intermediate temperatures $\left(24{ }^{\circ} \mathrm{C}\right.$ or $\left.30{ }^{\circ} \mathrm{C}\right)$, whereas only 6 lines had maximal mating success in the cold $\left(18^{\circ} \mathrm{C}\right)$ or extremely hot 
treatments $\left(36^{\circ} \mathrm{C}\right)$. For the DGRP-lines, 17 peaked in male mating success at intermediate temperature $\left(24^{\circ} \mathrm{C}\right), 9$ at cold temperature $\left(18{ }^{\circ} \mathrm{C}\right)$ and the remaining four at $30^{\circ} \mathrm{C}$ (note that the DGRP-lines were not evaluated under the extreme treatment $\left(36^{\circ} \mathrm{C}\right.$; see Fig. 1$)$. However, note that the relationship between male mating success and temperature was often quite flat in the range between 18 and $24{ }^{\circ} \mathrm{C}$, after which it dropped (Fig. 1). Taken together, these results suggest a genetically quite invariant intermediate temperature optimum and more or less flat fitness peak around $24{ }^{\circ} \mathrm{C}$ (Fig. 2). Thus, we found no evidence for any statistically significant difference between genotypes in the location of this fitness optimum and neither any evidence for different slopes of the thermal response curves or their curvatures (Table 3).

Using our statistical power simulation we were able to put a minimum bound on the genetic variation in thermal plasticity (variation in the effect of our Line x Temp interaction) (Fig. 3).

The main conclusion from these simulations is that our statistical power is high enough under realistic parameter values, meaning that we should have detected a large GEI:s if they had existed (Fig. 3). The magnitude of the GEI we recorded in these experiments can explain at most $4 \%$ of variation in mating rate. For instance, our statistical power approaches one with an effect size of 0.03 (treating temperature as a continuous variable) and 0.15 (treating temperature as a categorical variable)(Fig. 3). Finally, at $18^{\circ}$ and $30^{\circ} \mathrm{C}$ there was no detectable correlations between the mating rate of the hemi-clones and our DGRP lines. At $24^{\circ} \mathrm{C}$, there was a slightly stronger and significant correlation between the mating rates of the 313 DGRP and hemi-clonal males (Fig. 4). 
317 5). This shows that for these 10 DGRP-lines, the slopes of the thermal reaction norms

318 differed, although the effect was significant only in the first experimental block (Fig. 5; Table

$3195)$.

\section{Discussion}

322 Evolutionary change requires genetic variation in the traits under selection (Blows \&

323 Hoffmann 2005). This basic requirement for evolutionary change also applies to a trait like

324 thermal plasticity, and the evolution of thermal plasticity will require genetic variation in the

325 slopes of thermal reaction norms. In this study, we have found significant genetic variation in

326 male mating rates, using two different approaches: a pure-clonal approach (using a subset of

327 un-manipulated DGRP-lines bred by Mackay et al. 2012) and a hemi-clonal approach (Abbott

328 and Morrow 2011), where these DGRP-lines were introduced into an outbred $\mathrm{LH}_{\mathrm{M}}$

329 background (Fig. 1). Using these two complementary experimental approaches, we found no

330 statistically significant variation in the reaction norm of male mating rate to temperature in the

331 different lines (Figs. 1, 3). This shows that although all these lines altered their mating rates in

332 relation to temperature (i.e. phenotypic plasticity; Fig. 1, Table 1-4) the changes were parallel

333 and all lines responded in a similar manner. This implies that genetic variation in thermal

334 plasticity for male mating success is low (Fig. 1), explaining at most $4 \%$ of the variation (Fig.

335 3). Similar conclusions apply to male locomotory performance (Fig. 2), where we also did not

336 find any evidence for significant GEI (Table 4).

The lack of strong GEI:s for these two behavioural traits contrasts our findings of a significant

GEI for male heating rate, a physiological performance trait, measured using thermal imaging

340 (Fig. 5), where we did find evidence for GEI (Table 5). Heating rate is an important fitness 
341 trait for ectotherms because it might covary with ability to adjust to natural ambient

342 temperatures. It also measures the capacity of an individual to buffer itself against the

343 ambient environmental temperatures. The use of thermal imaging is a very powerful tool to

344 quantify genetic and phenotypic variation of a physiological trait like heating rate, as done in

345 previous studies of non-model organisms (Tattersall et al 2009; Tattersall and Cadena 2010;

346 Symonds and Tattersall 2010; Svensson and Waller 2013). The fact that the significant GEI

347 for thermal reaction norm slopes in these heating rates have no counterpart in the behavioural

348 assays of mating rates and locomotory assays (Figs. 1-2; Tables 1-4) might be biologically

349 important. Behavioural traits and life-history traits are further downstream than the

350 physiological traits are from the genes that govern phenotypic traits (Price and Schluter 1991),

351 hence genetic variation on these grounds expected to be lower for such higher-level traits,

352 such as mating rate and locomotory performance.

Overall, and across all lines, male mating success was maximal at $24{ }^{\circ} \mathrm{C}$ (DGRP-lines) or at either $24{ }^{\circ} \mathrm{C}$ or $30{ }^{\circ} \mathrm{C}$ (Fig. 2), with a few exceptions (Fig. 1). This suggests that the thermal optimum for male mating success falls well within the normal temperature range Drosophila melanogaster will experience in North Carolina in the wild (Annual high temperature: $21.5^{\circ}$, Annual low temperature: $9.3^{\circ}$, Average temperature: $14.9^{\circ} \mathrm{C}$ (Daly 2000)), where these DGRP-lines originated (Mackay et al. 2012). Thus, although our results suggests limited evolutionary potential for thermal plasticity with respect to male mating success, they are consistent with males being locally adapted with respect to their local temperature regime, al. 2011). 
364 These DGRP lines were derived from field-caught flies and variation among these lines

365 should reflect naturally segregating genetic variation in the source population (Mackay et al.

366 2012). Using a statistical power simulation (Fig. 3), we were able to put a minimum bound on

367 the amount of variation in reaction norms in our clonal lines. The line effect had a standard

368 deviation of $<0.5$, which implies that variation in mating rate was at a maximum less than

3690.01 matings for any given temperature. Comparing the slopes of the reaction norms from

370 optimal temperature condition $\left(24^{\circ} \mathrm{C}\right)$ to extreme temperature condition $\left(36^{\circ} \mathrm{C}\right)$, we conclude

371 that the standard deviation in slopes is likely $<0.01$. This effect covers only about $4 \%$ of the

372 total variation in male mating success $($ Line $=11 \%$, Temp $=58 \%$, Block $=21 \%$, Line:Temp $=$

$3734 \%$, Residual $=5 \%$ ). This means that lines varied less than around \pm 0.008 matings (in 10 min)

374 per $1^{\circ} \mathrm{C}$ (Fig. 3). Whether this low amount of variation in thermal reaction norms would allow

375 for evolution of adaptive phenotypic plasticity is an open question and depends on several

376 other ecological and evolutionary factors, including population size, the strength of selection,

377 the rate of environmental change, generation time, and intrinsic rate of increase (Hoffmann

378 2010; Chevin et al. 2010). However, we note that the effect sizes in these power calculations

379 are minimum effect sizes, and the true amount of genetic variation in thermal plasticity might

380 be considerably lower.

382 One concern is that mating rate is the product of the behaviour of multiple individuals

383 interacting, so it is not only the male's behaviour that matters, but also the female's

384 preference. For instance, LHm females prefer males from some of the DGRP-lines more than

385 males from other DGRP-lines. A second concern is that it is the additive genetic variation that

386 determines the evolutionary potential of a population, yet the hemi-clones still share the

387 same half-genome, so any epistatic effects arising from interactions between chromosomes

388 within the DGRP half will also be included. Our experimental design is for these reasons 
conservative with respect to our ability to detect significant GEI:s, since the line-effects will partly also include non-additive effects. Additionally, there might exist variation in latency to mate after a disturbance between lines, and this might be of some concern. However, any differences in willingness to mate after disturbance will be captured by the line effect in our statistical analyses. This means that lines might differ not only mating rate per se but also in their willingness to mate at each temperature. This variation in willingness to mate after a disturbance would not interfere with detecting GEI:s in mating rate, unless there was an interaction between the latency to mate and temperature treatment.

For the hemi-clonal lines, epistatic effects would not be included by the line factor, since our starting iso-genetic lines (30) were homozygous at all loci. Thus, epistatic interactions with the outbred (LHm) genetic background would not be included in the line effect, and would become part of the error variance. Such epistatic genetic variance would represent hidden genetic variation that we were not able to detect with our hemi-clonal lines (Huang et al. 2012; Mackay 2014). Epistatic variance of traits related to mating success, such as courtship, have been demonstrated for other species of flies (Meffert et al. 2002). In these previous studies it has been shown that such epistatic variance can be converted to additive genetic variance following population bottlenecks (Meffert et al. 2002). From a theoretical viewpoint, traits that are closely related to fitness such as male mating success (a major fitness component) are expected to show low additive genetic variance, due to the depleting effects of strong directional sexual selection (Rowe \& Houle 1996). Directional sexual selection should therefore expect reduce the additive genetic variance fraction for male mating success, resulting in a relatively higher fraction of the remaining genetic variation being non-additive, reflecting either epistatic (Meffert et al. 2002) or dominance variance (Merilä \& Sheldon 2002). Such non-additive genetic variance for male mating success could potentially explain 
414 the low concordance between male mating success in the DGRP-lines and the hemi-clonal

415 lines (Fig. 4). This interpretation of high epistatic variance for male mating success in these

416 DGRP-lines would be consistent with previous studies of these DGRP-lines, where high

417 epistatic variance was found for a number of other fitness-related traits, including cold

418 tolerance (measured as chill coma recovery) (Huang et al. 2012).

420 Our results have some implications for the prospects of evolutionary rescue through the

421 evolution of adaptive phenotypic plasticity (Chevin et al. 2013) and by sexual selection

422 (Candolin \& Heuschele 2008). Previous laboratory experiments on several species of selection improving the rate of evolution of local adaptation to novel stressful environments, such as thermally challenging environments. The results in the present study add to this small

427 but growing body of literature, and indicate that thermal plasticity for male mating success is unlikely to evolve, as the genetic variation in thermal reaction norms is limited (Fig. 3). Some theoretical models suggest that sexual selection could improve environmental adaptation at low demographic costs, due to purging of deleterious alleles in males (Agrawal 2001; Siller (cited above) give only weak support to these models. Thus, our results provide only limited support to the hypothesis that sexual selection could act as an evolutionary rescuer of populations experiencing rapid environmental change (Candolin \& Heuschele 2008).

436 Our results also agree with other research in this area showing that evolutionary responses to 
438 Kellermann et al. 2009; Mitchell \& Hoffmann 2010; Hoffmann 2010; Kelly et al. 2012; Kelly

439 et al. 2013; Kristensen et al. 2015). In particular, ectotherms, particularly those living in

440 tropical areas that already experience temperatures close to their upper thermal tolerance

441 limits might have a reduced capacity to adapt to higher temperatures via evolutionary means

442 (Araujo et al. 2013; Kristensen et al. 2015) (Fig 2). Insights from studies of niche

443 conservatism also suggests that it might be difficult for many species to evolve new

444 physiological limits (Parsons 1982; Kimura \& Beppu 1993; Wiens \& Graham 2005;

445 Kellermann et al. 2009; Hoffmann 2010). For example, the invasive species Drosophilia

446 subobscura has a range in the Americas that is restricted to climates that are similar to those

447 found in its native range in Europe (Prevosti et al. 1988; Gilchrist et al. 2008; Huey \& Pascual

448 2009; Hoffmann 2010). However, some natural Drosophila populations have adapted to their

449 local climates (Trotta et al. 2006). For instance, warm-adapted populations in India have

450 higher levels of desiccation resistance and melanism compared with cold-adapted populations

451 (Parkash et al. 2008). Similarly, populations in Africa are more viable at warm temperatures

452 than temperate populations (Bouletreau-Merle et al. 2003; David et al. 2004; David et al.

453 2005; Hoffmann 2010). Other laboratory studies have shown that populations might have the

454 capacity to adapt to temperature via evolutionary adaptation (Hoffmann 2010; Latimer et al.

455 2011; Mukuka et al. 2010; Hoffmann et al. 2013; van Heerwaarden and Sgro 2013;

456 Blackburn et al. 2014; van Heerwaarden at al. 2016). For example, in some laboratory

457 experiments, Drosophilia have been successfully selected for increased survival after cold and

458 heat shocks (Bubliy \& Loeschcke 2005). Finally, it might be that the expression of additive

459 genetic variation for heat tolerance is contingent on developmental temperature (van

460 Heerwaarden at al. 2016). For instance, two rainforest Drosophila species exhibited

461 significant levels of additive genetic variation when raised in warmer environments, but not

462 when raised at $25^{\circ} \mathrm{C}$ (van Heerwaarden at al. 2016). 


\section{Conclusions}

464 The capacity of natural populations of Drosophila melanogaster to adapt evolutionarily (i.e.

465 via changing the genetic composition of the population) to novel thermal conditions through

466 the evolution of adaptive phenotypic plasticity remains an open question. In this study, we

467 were not able to detect any significant genetic variation in thermal reaction norms to different

468 thermal environments in either the DGRP-lines or the hemi-clonal lines. However, we were

469 able to put a lower bound on the amount of genetic variance in thermal plasticity. Isogenic

470 lines such as these DGRP-lines in combination with hemi-clonal approaches offer

471 opportunities to quantify genetic variation in phenotypes where the underlying genotypes are

472 known and line-differences can attributed to genetic differences without the need for complex

473 breeding designs (Abbott \& Morrow 2011). Such isogenic lines could also be raised in

474 different temperatures in the future, which might reveal that significant genetic variation

475 exists, but this variation might depend on temperatures experienced during the larval

476 development stage (van Heerwaarden at al. 2016). It is possible that GEI:s might be more

477 pronounced among juveniles, and that strong selection during these earlier life stages might

478 have reduced additive genetic variance in thermal reaction norms that could be detected

479 during the adult stage (cf. Martinossi-Allibert et al. 2016). In the present study, we were not

480 able to detect any significant genetic variation in thermal plasticity in adult male mating

481 success or locomotion.

\section{$482 \quad$ Figure Legends}

484 Fig 1. Thermal reaction norms of male mating success estimated for of each pure DGRP

485 (black) and hemi-clonal (empty) DGRP-line in relation to experimental temperature

486 treatments. Numbers above each sub-panel refer to the DGRP-lines described in Mackay et al. 
487 (2012). Although temperature affects mating rates in all lines and often peaks at intermediate

488 temperatures, there is no evidence for any genotype-by-environment interaction with respect

489 to temperature, i.e. the mating success of the different lines are similarly affected across

490 environmental treatments. Mating rate is the number of copulations that were recorded in a

491 vial after 10 minutes (for the hemiclones) and after 15 minutes (for the pure clones). The

492 mating assay was only performed for some lines with either only the hemi-clones $(303,486)$

493 or only the pure lines $(305,315)$. Confidence intervals $(95 \%)$ are shown as vertical lines.

Fig 2. Temperature-related male performance for the hemi-clonal males showed as male between lines in thermal reaction norms (slopes) is low (Fig. 1). Hence, there is no evidence for significant genetic variation in the thermal reaction norms (Fig. 1). Each data point represents the mean performance of each line at each temperature treatment.

Fig 3. Power plots to detect significant GEI:s (reflected as Line*Temp interactions) for male experimental factor (right plot). Comparing the slopes of the reaction norm (left panel) from optimal temperature to extreme (hemiclonal lines: $24^{\circ}$ to $36^{\circ} \mathrm{C}$; pure DGRP-lines: $24^{\circ}$ to $30^{\circ}$ C), we found that the standard deviation in slope is likely to be $<0.01$ for the hemi-clonal lines and $<0.025$ for the pure DGRP-lines. This means that lines varied in less \pm 0.008 matings (per $10 \mathrm{~min}$ ) per $1^{\circ} \mathrm{C}$. Treating temperature as discrete (right panel), the standard deviation of this Line*Temp effect is most likely $<0.07$ for the hemi-clonal lines and $<0.12$

510 for the pure clonal lines. This means that the variation in mating rate is maximally $<0.01$ 
511 matings for a given temperature. These are minimum effect sizes, and the true variation in

512 thermal plasticity is likely to be lower. R-code for these power simulations are provided on

513 Dryad. Each data point represents 1000 simulations (hemi-clonal: $\mathrm{n}=7$ and pure-clonal: $\mathrm{n}=3$

514 replicates per line $\mathrm{n}=30$ ).

516 Fig. 4. Correlations between mating rates (at $10 \mathrm{~min}$ and 15 between our hemi-clonal and

517 DGRP lines, measured at three different temperatures (measured at $18{ }^{\circ} \mathrm{C}$ ("cold" = white), 24

$518{ }^{\circ} \mathrm{C}$ ("optimal" = gray) and $30{ }^{\circ} \mathrm{C}$ ("hot" = black). We studied a total of 28 Lines per

519 temperature treatment, i.e. the total number of datapoints in this graph is 84). The "random"

520 Lhm genetic background in our hemi-clonal lines likely has a large effect on mating rate,

521 since the mating rates the DGRP-lines, put either in to hemi-clones or measured as pure

522 clones show only weak non-significant relationships (All: $\mathrm{r}=0.12, P=0.24, \mathrm{~N}=84,18 \mathrm{C}$ : $\mathrm{r}$

$523=0.08, P=0.68, \mathrm{~N}=29 ; 24 \mathrm{C}: \mathrm{r}=0.37, P=0.05, \mathrm{~N}=29 ; 30 \mathrm{C}: \mathrm{r}=0.10, P=0.61, \mathrm{~N}=29)$. The lack

524 of strong significant correlations between the mating rates of the different lines in different

525 genetic backgrounds indicates low additive genetic variance in male mating success and

526 implies strong epistatic effects on mating rate (Huang et al. 2012), as our hemi-clonal and

527 pure-clonal lines will only share the additive effects of their genotypes.

Fig 5. A) Heating rates of 10 DGRP lines after exposer to a cool shock $5^{\circ} \mathrm{C}$ for 3 minutes and

530 then allowed to recover at room temperature for 30 seconds. Two experimental blocks were

531 performed of these same 10 DGRP lines. Thermal images were taken every 5 seconds.

532 Heating rate was significantly variable between lines in block 1 but not in block 2 (Table 5). 


\section{Figures and Tables}

539 Table 1. Analysis of variance (ANOVA) for the mating rate in hemi-clonal males. Line

$540(\mathrm{~N}=30)$ and temperature $\left(\mathrm{N}=4 ; 18,24,30,36^{\circ} \mathrm{C}\right)$ were both treated as categorical factors. We

541 used the first mating observation at 10 minutes to avoid double counting matings at the next

542 observation time 20 minutes. Here, a significant Line $\mathrm{x}$ Temp interaction would be indicative

543 of a GEI and reveal significant genetic variation (greater than zero) in plasticity in our hemi-

544 clonal males. Block is a categorical factor $(\mathrm{N}=2)$, which controls for differences in the two experimental runs. See table S1 in the supplementary material and a model wherein mating rate is treated as a proportion.

\begin{tabular}{|l|r|l|l|l|l|l|}
\hline Term & DF & SSE & MSE & F-value & P-value & Significance \\
\hline Line & 29 & 4.54 & 0.16 & 2.37 & $<0.0001$ & $* * * *$ \\
\hline Temp & 3 & 2.48 & 0.83 & 12.51 & $<0.0001$ & $* * * *$ \\
\hline Block & 1 & 0.3 & 0.3 & 4.52 & 0.034 & $*$ \\
\hline Line $x$ Temp & 87 & 4.88 & 0.06 & 0.85 & 0.83 & ns \\
\hline Residuals & 870 & 57.38 & 0.07 & & & \\
\hline
\end{tabular}

547 
556 Table 2. Analysis of variance (ANOVA) for the mating rate of the DGRP males. Line (N=32)

557 and temperature $\left(\mathrm{N}=3 ; 18,24,30^{\circ} \mathrm{C}\right)$ were both treated as categorical factors. We used the first 558 observation time at 15 minutes to avoid double counting matings at the next observation time 55930 minutes. A significant Line x Temp interaction would be indicative of a GEI.

\begin{tabular}{|l|r|l|l|l|l|l|}
\hline Term & DF & SSE & MSE & F-value & P-value & Significance \\
\hline Line & 31 & 5.22 & 0.17 & 3.55 & $<0.0001$ & $* * * *$ \\
\hline Temp & 2 & 1.31 & 0.66 & 13.82 & $<0.0001$ & $* * * *$ \\
\hline Line $\times$ Temp & 58 & 2.35 & 0.04 & 0.86 & 0.752 & ns \\
\hline Residuals & 172 & 8.16 & 0.05 & & & \\
\hline
\end{tabular}

560

561

562

563

564

565

566

567 
573 Table 3. Analysis of covariance (ANOVA) for the mating rate hemi-clonal males. Here Line

$574(\mathrm{~N}=30)$ is treated as a categorical factor and temperature is treated as a continuous variable.

575 The quadratic effect of temperature $\left(\mathrm{Temp}^{2}\right)$ allows the model to detect any curvature in the

576 reaction of mating rate to temperature. We used the first observation time at 10 minutes to

577 avoid double counting matings at the next observation time 20 minutes. Here, a significant

578 Line $\mathrm{x}$ Temp interaction would be indicative of a GEI, and indicate significant genetic

579 variation (greater than zero) in plasticity in our hemi-clonal males. Block is a categorical

580 factor $(\mathrm{N}=2)$, which controls for differences in the two experimental runs.

\section{1}

\begin{tabular}{|l|l|l|l|l|l|l|}
\hline Term & DF & SSE & MSE & F-value & P-value & Significance \\
\hline Line & 29 & 4.54 & 0.16 & 2.41 & $<0.0001$ & $* * * *$ \\
\hline Temp & 1 & 0.02 & 0.02 & 0.34 & 0.557 & ns \\
\hline Temp $^{2}$ & 1 & 2.39 & 2.39 & 36.81 & $<0.0001$ & $* * * *$ \\
\hline Block & 1 & 0.31 & 0.31 & 4.82 & 0.028 & $*$ \\
\hline Line $x$ Temp & 29 & 2.27 & 0.08 & 1.2 & 0.212 & ns \\
\hline Line $x$ Temp & 29 & 1.67 & 0.06 & 0.89 & 0.641 & ns \\
\hline Residuals & 900 & 58.38 & 0.06 & & & \\
\hline
\end{tabular}

582

583 
591 Table 4. Analysis of locomotion performance in the hemi-clonal lines $(\mathrm{N}=30)$. Locomotion

592 is the speed (mm/seconds) of the fastest hemiclonal male (7 per vial) to walk up the side of

593 the vial (repeated 3 times for each line) at the different experimental temperatures. We

594 performed a two-way analysis of variance (ANOVA) with locomotion time the as the

595 dependent variable and line, temperature and their interaction as independent dependent

596 factors.

597

\begin{tabular}{|l|r|l|l|l|l|l|}
\hline Term & DF & SSE & MSE & F-value & P-value & Significance \\
\hline Line & 29 & 4197.69 & 144.75 & 1.76 & 0.009 & $* *$ \\
\hline Temp & 3 & 7449.08 & 2483.03 & 30.22 & $<0.0001$ & $* * * *$ \\
\hline Line $x$ Temp & 87 & 5691.16 & 65.42 & 0.8 & 0.907 & ns \\
\hline Residuals & 592 & 48635.14 & 82.15 & & & \\
\hline
\end{tabular}

598

599

600

601

602

603 
611 Table 5. Analysis of variance (ANOVA) for the heating rate of DGRP males. 2 replicates of

612 Lines $(\mathrm{N}=10)$. Time is measured in seconds. A thermal image was taken at each time point.

613 Here, a significant Line $\mathrm{x}$ Time interaction would be indicative of significant variation in 614 heating rate between lines. However, a significant Time x Line x Block effect complicates 615 this interpretation. Block is a categorical factor $(\mathrm{N}=2)$, which controls for differences in the 616 two experimental runs.

\begin{tabular}{|l|r|l|l|l|l|l|}
\hline Term & DF & SSE & MSE & F-value & P-value & Significance \\
\hline Time & 1 & 135.14 & 135.14 & 290.3 & $<0.0001$ & $* * *$ \\
\hline Line & 9 & 42.62 & 4.74 & 10.17 & $<0.0001$ & $* * *$ \\
\hline Block & 1 & 35.44 & 35.44 & 76.13 & $<0.0001$ & $* * *$ \\
\hline Time x Line & 9 & 9.46 & 1.05 & 2.26 & 0.024 & $*$ \\
\hline Time x Block & 1 & 3.94 & 3.94 & 8.47 & 0.004 & $* *$ \\
\hline Line x Block & 9 & 16.48 & 1.83 & 3.93 & 0.0002 & $* * *$ \\
\hline Time x Line x Block & 9 & 8.47 & 0.94 & 2.02 & 0.04 & $*$ \\
\hline Residuals & 95 & 44.22 & 0.47 & & & \\
\hline
\end{tabular}

617

618 
bioRxiv preprint doi: https://doi.org/10.1101/166801; this version posted July 21,2017 . The copyright holder for this preprint (which was not certified by peer review) is the author/funder, who has granted bioRxiv a license to display the preprint in perpetuity. It is made available under aCC-BY-NC 4.0 International license.

\section{1}

622

623

624

625

626

627

628

629

630

631

632

633

634

635

636

637

638 

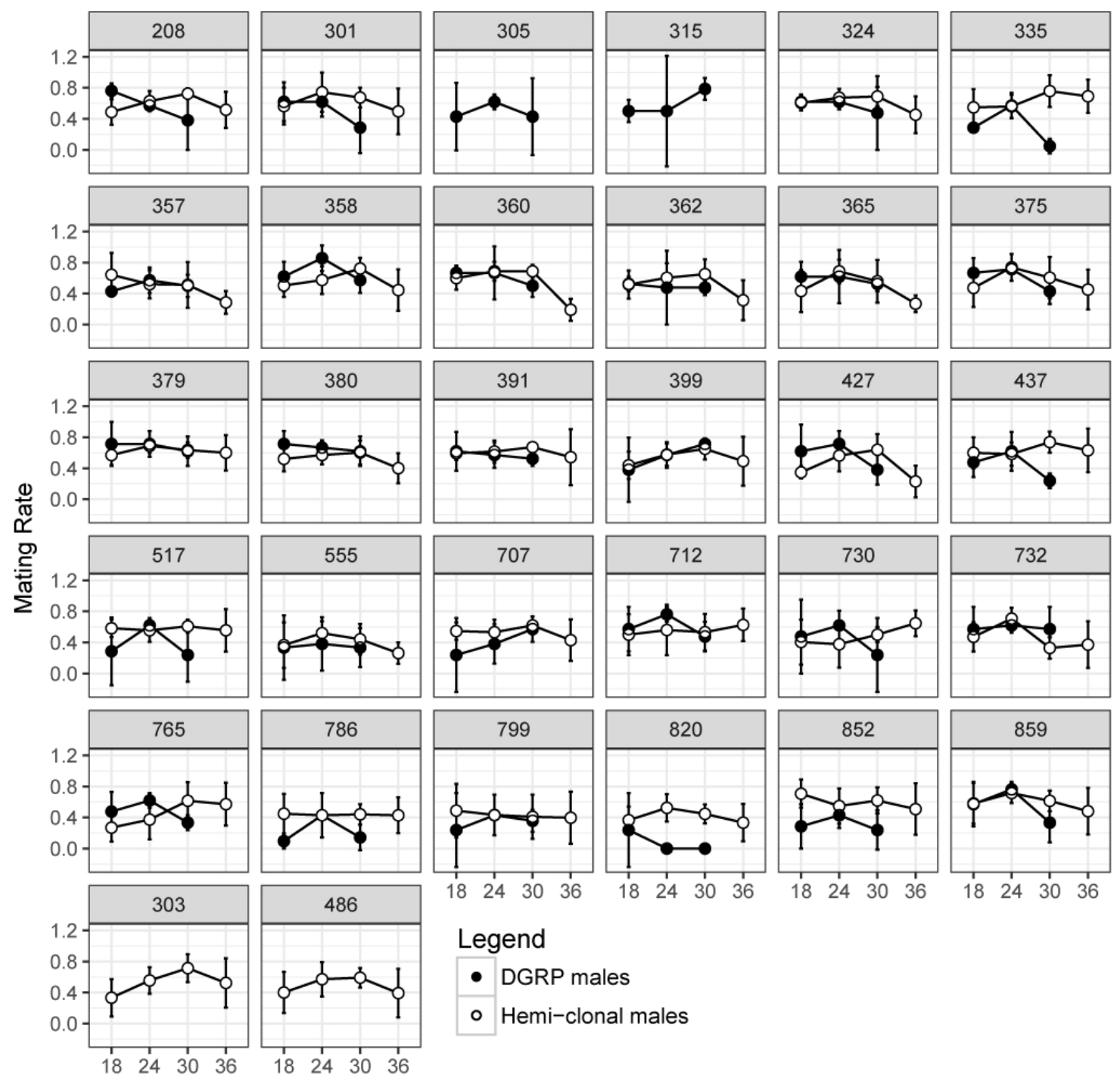

642

Temperature

643

644

645

\section{Legend}

- DGRP males

- Hemi-clonal males 
bioRxiv preprint doi: https://doi.org/10.1101/166801: this version posted July 21,2017 . The copyright holder for this preprint (which was not certified by peer review) is the author/funder, who has granted bioRxiv a license to display the preprint in perpetuity. It is made available under aCC-BY-NC 4.0 International license.

647

648

649

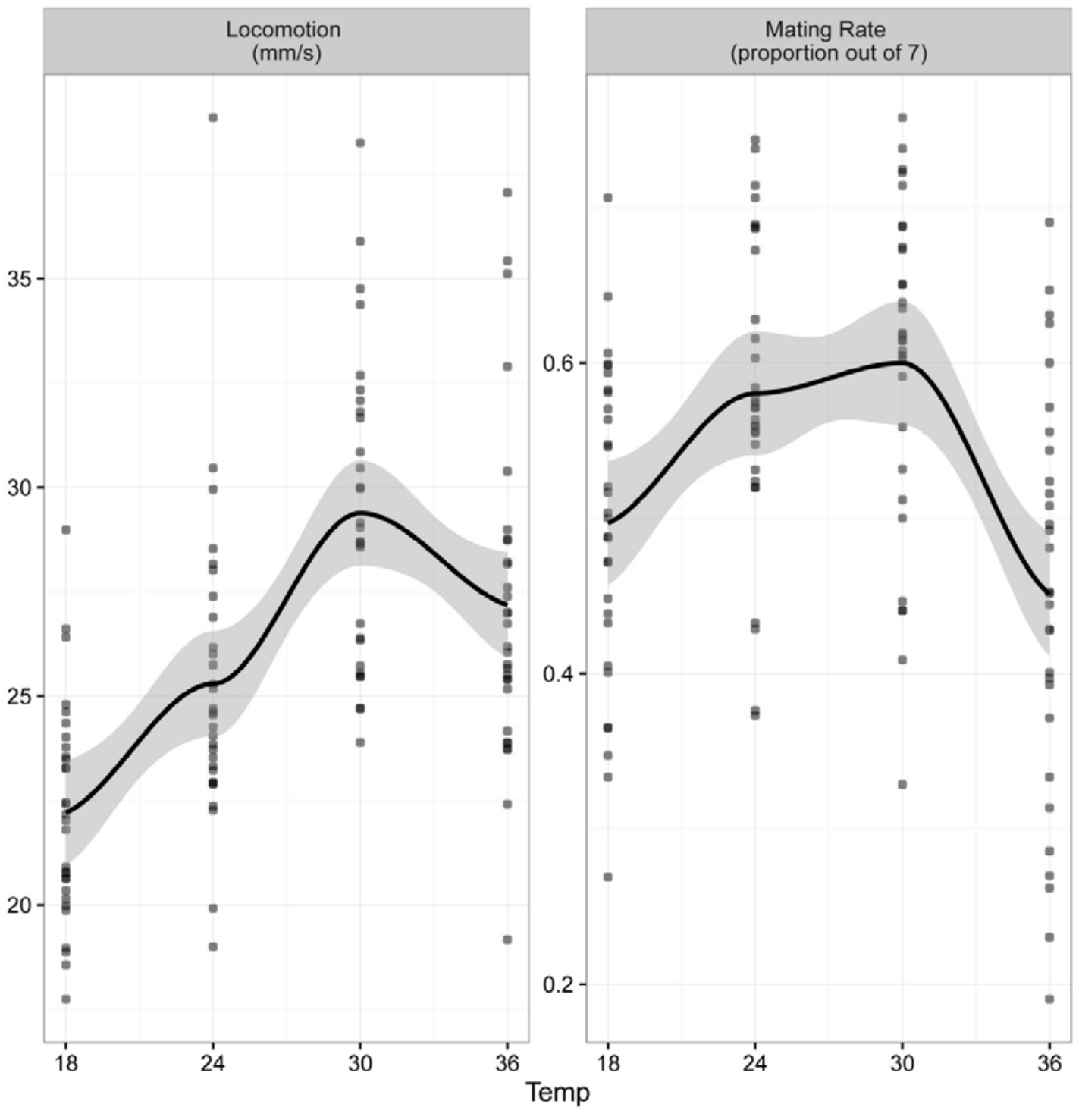

650

651

652

653 
bioRxiv preprint doi: https://doi.org/10.1101/166801: this version posted July 21, 2017. The copyright holder for this preprint (which was not certified by peer review) is the author/funder, who has granted bioRxiv a license to display the preprint in perpetuity. It is made available under aCC-BY-NC 4.0 International license.

654

655

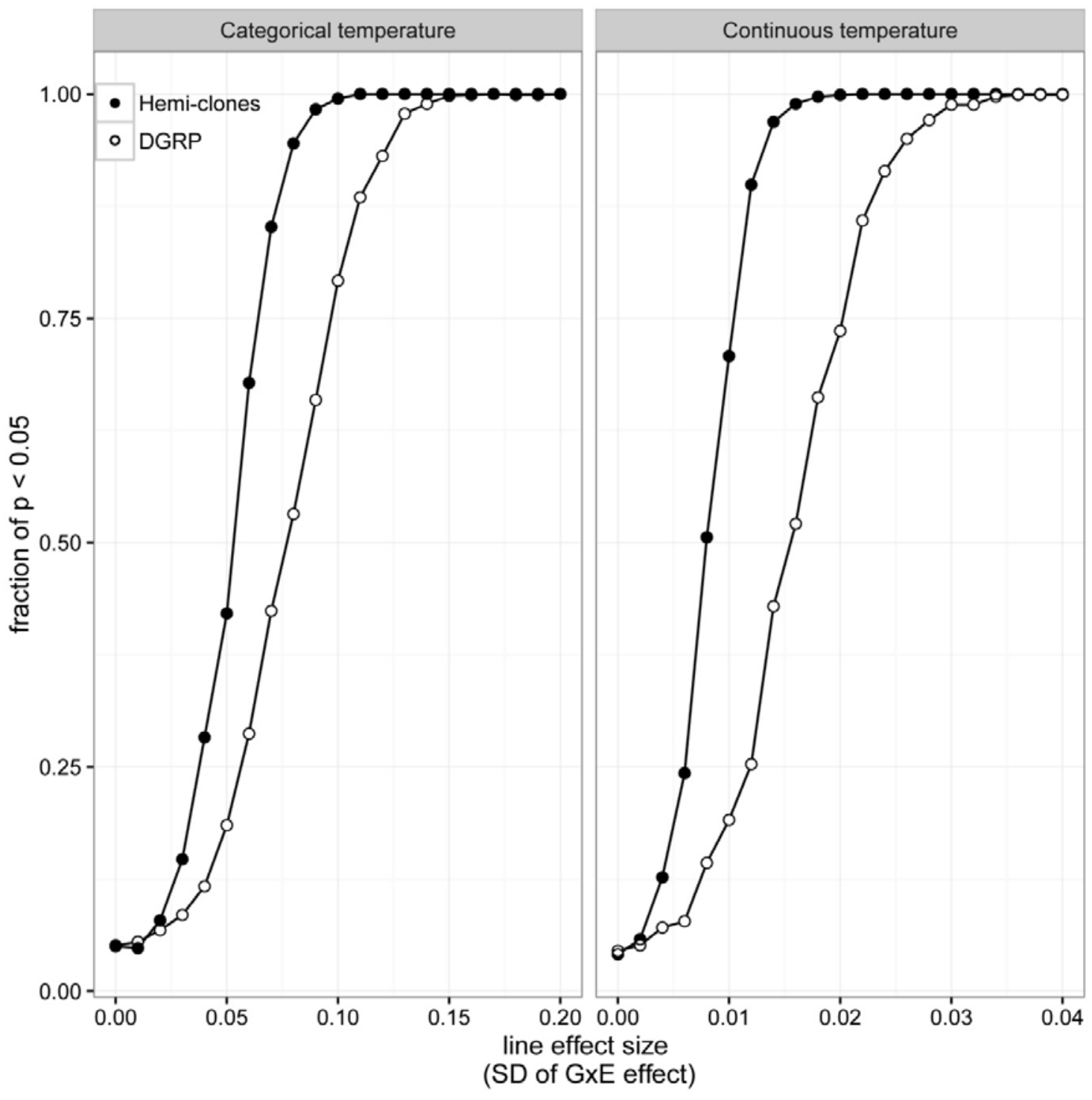

656

(SD of GxE effect)

657

658

659

660 
bioRxiv preprint doi: https://doi.org/10.1101/166801; this version posted July 21,2017 . The copyright holder for this preprint (which was not certified by peer review) is the author/funder, who has granted bioRxiv a license to display the preprint in perpetuity. It is made available under aCC-BY-NC 4.0 International license.

661

662

663

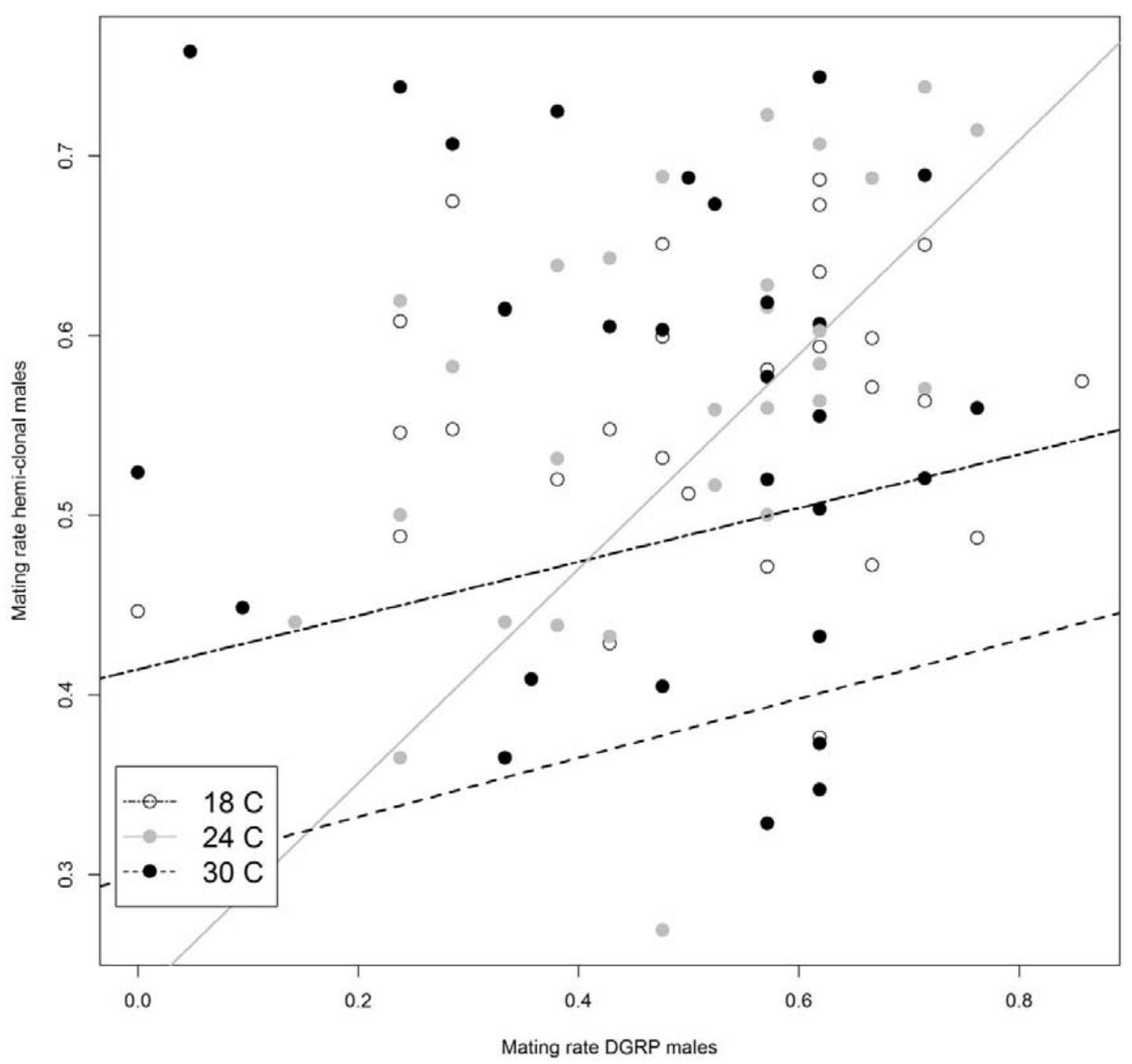

664

665

666

667

668 
bioRxiv preprint doi: https:/doi.org/10.1101/166801; this version posted July 212017 . The copyright holder for this preprint (which was not certified by peer review) is the author/funder, who has granted bioRxiv a license to display the preprint in perpetuity. It is made available under aCC-BY-NC 4.0 International license.

669

670

671

672

673

674

675

676

677

678

679
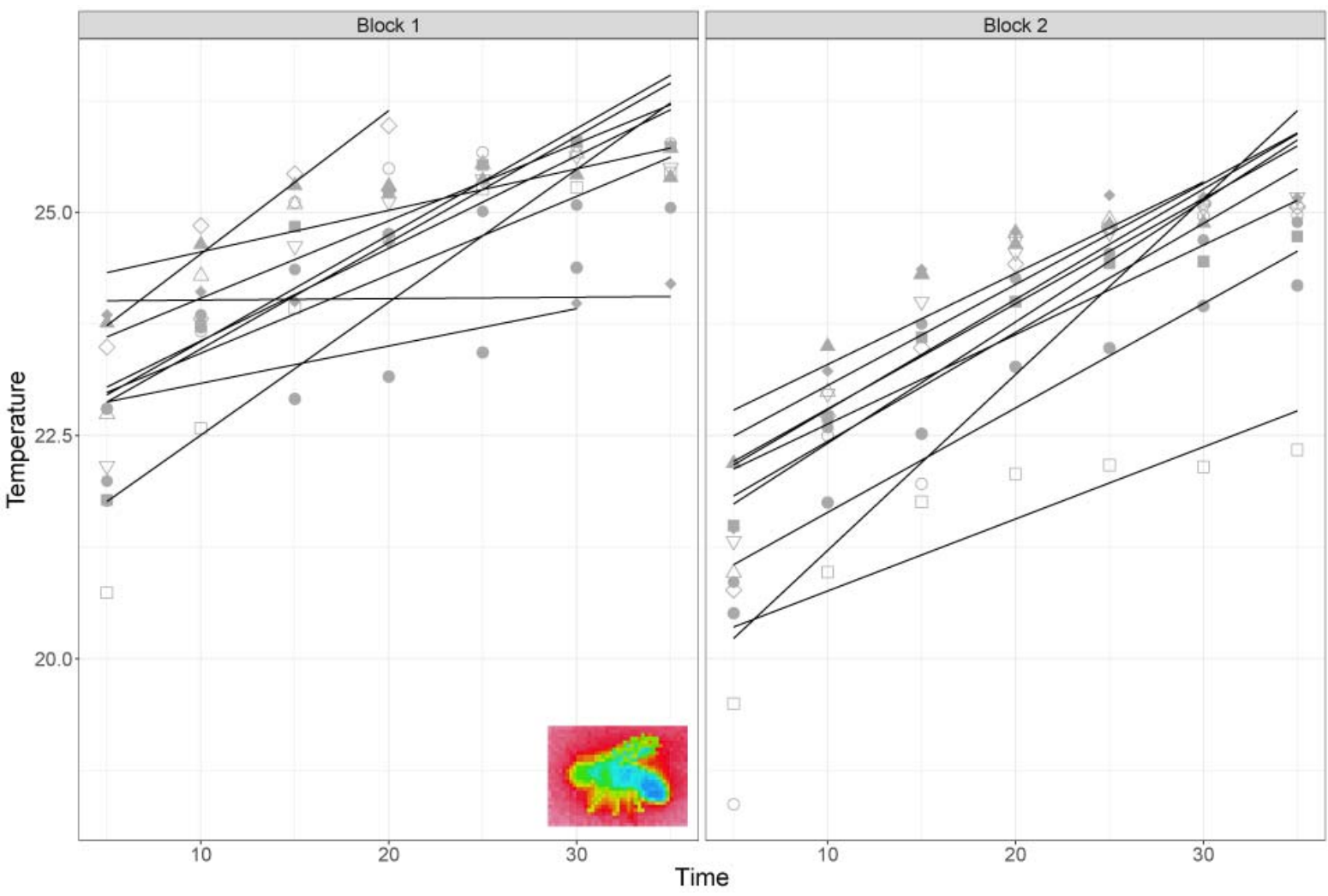

681

682

683

684 


\section{References}

690

Abbott, J. K. and E. H. Morrow. 2011. Obtaining snapshots of genetic variation using hemiclonal analysis. Trends Ecol. Evol. 26: 359-368.

Addo-Bediako, A., S. L. Chown and K. J. Gaston. 2000. Thermal tolerance, climatic variability and latitude. Proc. R. Soc. Lond., B, Biol. Sci. 267: 739-745.

Agrawal, A.F. 2001. Sexual selection and the maintenance of sexual reproduction. Nature 411: 692695.

Angiletta, M. J. 2009. Thermal adaptation: a theoretical and empirical synthesis. Oxford University Press, Oxford.

Angilletta, M. J., P. H. Niewiarowski and C. A. Navas. 2002. The evolution of thermal physiology in ectotherms. J. Therm. Biol. 27: 249-268.

Araujo, M. B., F. Ferri-Yanez, F. Bozinovic, P. A. Marquet, F. Valladares and S. L. Chown. 2013. Heat freezes niche evolution. Ecol. Lett. 16: 1206-1219.

Ayrinhac, A., V. Debat, P. Gibert, A. G. Kister, H. Legout, B. Moreteau, R. Vergilino, and J. R. David. 2004. Cold adaptation in geographical populations of Drosophila melanogaster: phenotypic plasticity is more important than genetic variability. Funct. Ecol. 5: 700-706.

Bennett, A. F. and R. E. Lenski. 1993. Evolutionary adaptation to temperature II. Thermal niches of experimental lines of Escherichia coli. Evolution 47: 1-12.

Blackburn, S., B. van Heerwaarden, V. Kellermann and C. M. Sgro. 2014. Evolutionary capacity of upper thermal limits: beyond single trait assessments. J. Exp. Biol. 217: 1918-1924.

Blows, M. W. and A. A. Hoffmann. 2005. A reassessment of genetic limits to evolutionary change. Ecology, 86: 1371-1384.

Bouletreau-Merle, J., P. Fouillet and J. Varaldi. 2003. Divergent strategies in low temperature environment for the sibling species Drosophila melanogaster and D. simulans: overwintering in extension border areas of France and comparison with African populations. Evol. Ecol. 17: 523-548.

Bradshaw, A. D. 1965 Evolutionary significance of phenotypic plasticity in plants. Adv. Genet. 13:115-155.

Bubliy, O. A. and V. Loeschcke. 2005. Correlated responses to selection for stress resistance and longevity in a laboratory population of Drosophila melanogaster. J. Evol. Biol. 18: 789-803.

Candolin, U. and J. Heuschele. 2008. Is sexual selection beneficial during adaptation to environmental change? Trends Ecol. Evol. 23: 446-452. 
720 Carter, A. J. R., T. M. Weier and D. Houle. 2009. The effect of inbreeding on fluctuating asymmetry

721 of wing veins in two laboratory strains of Drosophila melanogaster. Heredity 102.6: 563-572.

722 Charmantier, A., R. H. McCleery, L. R. Cole, C. Perrins, L. E. B. Kruuk and B. C. Sheldon. 2008.

723 Adaptive phenotypic plasticity in response to climate change in a wild bird population. Science, 320 :

724 800-803.

725 Chevin, L. M., R. Gallet, R. Gomulkiewicz, R.D. Holt, and S. Fellous. 2013. Phenotypic plasticity in 726 evolutionary rescue experiments. Philos. Trans. R. Soc. Lond., B, Biol. Sci. 368: 89-99.

727 Chevin, L. M., R. Lande and G. M. Mace. 2010. Adaptation, plasticity, and extinction in a changing

728 environment: Towards a predictive theory. PLoS Biol. 8: e1000357.

729 Chippindale, A. K., R. G. Jonathan and R. R. William. 2001. Negative genetic correlation for adult

730 fitness between sexes reveals ontogenetic conflict in Drosophila. Proc. Natl. Acad. Sci. 98.4: 1671-

7311675.

732 Daly, C., G. H. Taylor, W. P. Gibson, T. W. Parzybok, G. L. Johnson and P. A. Pasteris, 2000. High-

733 quality spatial climate data sets for the United States and beyond. Trans. ASAE 43: 1957-1967.

734 David, J. R., L. O. Araripe, M. Chakir, H. Legout, B. Lemos, G. Petavy, C. Rohmer, D. Joly and B.

735 Moreteau. 2005. Male sterility at extreme temperatures: a significant but neglected phenomenon for

736 understanding Drosophila climatic adaptations. J. Evol. Biol. 18: 838-846.

737 David, J. R., R. Allemand, P. Capy, M. Chakir, P. Gibert, G. Petavy and B. Moreteau. 2004.

738 Comparative life histories and ecophysiology of Drosophila melanogaster and D. simulans. Genetica

739 120: $151-163$.

740 Deutsch, C. A., J. J. Tewksbury, R. B. Huey, K. S. Sheldon, C. K. Ghalambor, D. C. Haak and P. R.

741 Martin. 2008. Impacts of climate warming on terrestrial ectotherms across latitude. Proc. Natl. Acad.

742 Sci. 105: 6668-6672.

743 Fox J. and S. Weisberg. 2011. An R Companion to Applied Regression. Sage, Thousand Oaks CA.

744 Gibert, P., B. Moreteau, G. Petavy, D. Karan and J. R. David. 2001. Chill-coma tolerance, a major

745 climatic adaptation among Drosophila species. Evolution 55: 1063-1068.

746 Gilchrist, G.W. 1996. A quantitative genetic analysis of thermal sensitivity in the locomotor

747 performance curve of Aphidius ervi. Evolution 50:1560-1572.

748

749

750

751

752

753

754

755

756

757

758

759
Gilchrist, G. W., L. M. Jeffers, B. West, D. G. Folk, J. Suess and R. B. Huey. 2008. Clinal patterns of desiccation and starvation resistance in ancestral and invading populations of Drosophila subobscura. Evol. Appl. 1: 513-523.

Gonzalez, A., O. Ronce, R. Ferriere and M. E. Hochberg. 2013. Evolutionary rescue: an emerging focus at the intersection between ecology and evolution. Philos. Trans. R. Soc. Lond., B, Biol. Sci. 368 : $1610-1631$.

Gosden, T.P., J. T. Waller and E. I. Svensson. 2015. Asymmetric isolating barriers between different microclimatic environments caused by low immigrant survival. Proc. R. Soc. Lond., B, Biol. Sci. 282: 2410-2459.

Hansen, T. F. and D. Houle. 2004. Evolvability, stabilizing selection, and the problem of stasis. Phenotypic integration: studying the ecology and evolution of complex phenotypes. Oxford University Press, Oxford, 130-150. 
760 Hoffmann, A. A. 2010. Physiological climatic limits in Drosophila: patterns and implications. J. Exp.

761 Biol. 213: 870-880.

762 Hoffmann, A. A., S. L. Chown and S. Clusella-Trullas. 2013. Upper thermal limits in terrestrial

763 ectotherms: how constrained are they? Funct. Ecol. 27: 934-949.

764 Holland, B. 2002. Sexual selection fails to promote adaptation to a new environment. Evolution 56:

$765 \quad 721-730$

766 Huang, W., S. Richards, M. A. Carbone, D. H. Zhu, R. R. H. Anholt, J. F. Ayroles, et al. 2012.

767 Epistasis dominates the genetic architecture of Drosophila quantitative traits. Proc. Natl. Acad. Sci.

768 109: 15553-15559.

769 Huey, R. B. and M. Pascual. 2009. Partial thermoregulatory compensation by a rapidly evolving 770 invasive species along a latitudinal cline. Ecology 90: 1715-1720.

Husby, A., D. H. Nussey, M. E. Visser, A. J. Wilson, B. C. Sheldon and L. E. B. Kruuk. 2010. Contrasting patterns of phenotypic plasticity in reproductive traits in two great tit (Parus major) populations. Evolution 64: 2221-2237.

Katayama, N., J.K. Abbott, J. Kjaerandsen, Y. Takahashi and E.I. Svensson. 2014. Sexual selection on wing interference patterns in Drosophila melanogaster. Proc. Natl. Acad. Sci. 111:15144-15148.

Kellermann, V., B. van Heerwaarden, C. M. Sgro and A. A. Hoffmann. 2009. Fundamental

Kellermann, V., J. Overgaard, A. A. Hoffmann, C. Flojgaard, J. C. Svenning and V. Loeschcke. 2012. phylogenetically. Proc. Natl. Acad. Sci. 109: 16228-16233.

Kelly, M. W., E. Sanford and R. K. Grosberg. 2012. Limited potential for adaptation to climate change

Kelly, M. W., R. K. Grosberg and E. Sanford. 2013. Trade-Offs, geography, and limits to thermal adaptation in a tide pool copepod. Am. Nat. 181: 846-854.

Kimura, M. T. and K. Beppu. 1993. Climatic adaptations in the Drosophila immigrans species group seasonal migration and thermal tolerance. Ecol. Entomol. 18: 141-149.

Kristensen, T. N., J. Overgaard, J. Lassen, A. A. Hoffmann and C. Sgro. 2015. Low evolutionary potential for egg-to-adult viability in Drosophila melanogaster at high temperatures. Evolution 69: 803-814.

Lande, R. 2009. Adaptation to an extraordinary environment by the evolution of phenotypic plasticity and genetic assimilation. J. Evol. Biol. 22:1435-1446.

792 Lande, R. 2014. Evolution of phenotypic plasticity and environmental tolerance of a labile quantitative character in a fluctuating environment. J. Evol. Biol. 27: 866-875. 
799 Mackay, T. F. C. 2014. Epistasis and quantitative traits: using model organisms to study gene-gene interactions. Nat. Rev. Genet. 15: 22-33.

801 Mackay, T. F. C., S. Richards, E. A. Stone, A. Barbadilla, J. F. Ayroles, D. H. Zhu, et al.. 2012. The

802 Drosophila melanogaster Genetic Reference Panel. Nature 482: 173-178.

803 Manenti, T., V. Loeschcke, N. N. Moghadam and J. G. Sorensen. 2015. Phenotypic plasticity is not 804 affected by experimental evolution in constant, predictable or unpredictable fluctuating thermal 805 environments. J. Evol. Biol. 28: 2078-2087.

806 Martinossi-Allibert I., G. Arnqvist and D. Berger. 2016. Sex-specific selection under environmental 807 stress in seed beetles. J. Evol. Biol. DOI: 10.1111/jeb.12996.

808 Mathur, V. and P. S. Schmidt. 2017. Adaptive patterns of phenotypic plasticity in laboratory and field 809 environments in Drosophila melanogaster. Evolution 71.2: 465-474.

810 Meffert, L.M., S.K. Hicks and J.L Regan. 2002. Nonadditive genetic effects in animal behavior. Am. 811 Nat. 160:198-213.

812 Merilä, J. and B.C. Sheldon. 1999. Genetic architecture of fitness and nonfitness traits: empirical 813 patterns and development of ideas. Heredity 83: 103-109.

814 Mitchell, K. A. and A. A. Hoffmann. 2010. Thermal ramping rate influences evolutionary potential 815 and species differences for upper thermal limits in Drosophila. Funct. Ecol. 24: 694-700.

Mukuka, J., O. Strauch, L. Waeyenberge, N. Viaene, M. Moens and R. U. Ehlers. 2010. Heat tolerance among different strains of the entomopathogenic nematode Heterorhabditis bacteriophora. Biocontrol 818 55: 423-434.

Murren, C.J., Auld, J.R., Callahan, H., Ghalambor, C.K., Handelsman, C.A., Heskel, M.A., et al. 2015. Constraints on the evolution of phenotypic plasticity: limits and costs of phenotype and plasticity. Heredity, 115:293-301.

822 Olsson, M., E. Wapstra, T. Schwartz, T. Madsen, B. Ujvari and T. Uller. 2011. In hot pursuit:

823 fluctuating mating system and sexual selection in sand lizards. Evolution 65:574-583.

824 Parkash, R., S. Rajpurohit and S. Ramniwas. 2008. Changes in body melanisation and desiccation 825 resistance in highland vs. lowland populations of D. melanogaster. J. Insect Physiol. 54: 1050-1056.

826 Parsons, P. A. 1982. Adaptive strategies of colonizing animal apecies. Biol. Rev. 57: 117-148.

827 Pigliucci, M. 2001. Phenotypic plasticity: beyond nature and nurture. John Hopkins University Press, 828 Baltimore.

829 Prevosti, A., G. Ribo, L. Serra, M. Aguade, J. Balana, M. Monclus and F. Mestres. 1988. Colonization 830 of America by Drosophila subobscura - experiment in natural populations that supports the adaptive 831 role of chromosomal inversion polymorphism. Proc. Natl. Acad. Sci. 85: 5597-5600.

832 Price, T. and D. Schluter. 1991. On the low heritability of life-history traits. Evolution 45: 853-861.

833 Punzalan, D., F. H. Rodd and L. Rowe. 2008. Sexual selection mediated by the thermoregulatory 834 effects of male colour pattern in the ambush bug Phymata americana. Proc. R. Soc. Lond., B, Biol. 835 Sci. 275:483-492. 
836 R Development Core Team. 2008. R: A language and environment for statistical computing. R

837 Foundation for Statistical Computing, Vienna, Austria. ISBN 3-900051-07-0, URL http://www.R-

838 project.org.

839 Roberts, S.P., Marden, J.H., and Feder, M.E. 2003. Dropping like flies: environmentally induced 840 impairment and protection of locomotor performance in adult Drosophila melanogaster. Physiol.

841 Biochem. Zool. 76:615-621.

842 Roff, D.A. 1997. Evolutionary quantitative genetics. Chapman and Hall, New York.

843 Rowe, L. and D. Houle. 1996. The lek paradox and the capture of genetic variance by condition

844 dependent traits. Proc. R. Soc. Lond., B, Biol. Sci. 263: 1415-1421.

845 Rundle, H.D., S.F. Chenoweth, and M.W. Blows. 2006. The roles of natural and sexual selection

846 during adaptation to a novel environment. Evolution 60: 2218-2225

847 Schlichting, C. D. and M. Pigliucci. 1998. Phenotypic evolution: a reaction norm perspective. Sinauer 848 Associates Incorporated, Sunderland.

849 Sgrò, C.M., Terblanche, J.S., and Hoffmann, A.A., 2016. What can plasticity contribute to insect 850 responses to climate change? Annu. Rev. Entomol. 61:433-451.

851 Siller, S. 2001. Sexual selection and the maintenance of sex. Nature 411:689-695.

852 Sisodia, S. and B. N. Singh. 2010. Resistance to environmental stress in Drosophila ananassae:

853 latitudinal variation and adaptation among populations. J. Evol. Biol. 23: 1979-1988.

854 Stevenson, R. D. 1985. The relative importance of behavioral and physiological adjustments

855 controlling body temperature in terrestrial ectotherms. Am. Nat. 126: 362-386.

856 Svensson, E. I. and J. T. Waller. 2013. Ecology and sexual selection: evolution of wing pigmentation 857 in Calopterygid damselflies in relation to latitude, sexual dimorphism and speciation. Am. Nat.

$858 \quad$ 182:174-195.

859 Symonds, M. R. R. and G. J. Tattersall. 2010. Geographic variation in bill size across bird species

860 provides evidence for Allen's rule. Am. Nat. 176:188-197.

861 Tattersall, G. J., D. V. Andrade, and A. S. Abe. 2009. Heat exchange from the toucan bill reveals a 862 controllable vascular thermal radiator. Science 325:468-470.

863 Tattersall, G. J. and V. Cadena. 2010. Insights into animal temperature adaptations revealed through

864 thermal imaging. Imaging Sci. J. 58:261-268.

865 Taylor, M.L., T. A. R. Price, A. Skeats and N. Wedell. 2015. Temperature can shape a cline in

866 polyandry, but only genetic variation can sustain it over time. Behav. Ecol. 27:462-469.

867 Trotta, V., F. C. F. Calboli, M. Ziosi, D. Guerra, M. C. Pezzoli, J. R. David and S. Cavicchi. 2006.

868 Thermal plasticity in Drosophila melanogaster: A comparison of geographic populations. BMC Evol.

869 Biol., 6: 67.

870 Visser, M. E. 2008. Keeping up with a warming world; assessing the rate of adaptation to climate

871 change. Proc. R. Soc. Lond., B, Biol. Sci. 275: 649-659.

872 Whitlock, M.C. and A.F. Agrawal. 2009. Purging the genome with sexual selection: reducing mutation

873 load through selection on males. Evolution 63: 569-582. 
bioRxiv preprint doi: https://doi.org/10.1101/166801; this version posted July 21, 2017. The copyright holder for this preprint (which was not certified by peer review) is the author/funder, who has granted bioRxiv a license to display the preprint in perpetuity. It is made available under aCC-BY-NC 4.0 International license.

874 Wiens, J. J. and C. H. Graham. 2005. Niche conservatism: Integrating evolution, ecology, and 875 conservation biology. Annu. Rev. Ecol. Evol. Syst. 36:519-39.

876

877

878

Yukilevich, R. 2013. Tropics accelerate the evolution of hybrid male sterility in Drosophila. Evolution 67:1805-1814.

879

880

881

882 